\section{Reseña / Guía para la elaboración de materiales educativos II. Piezas sonoras}

Ariel Levatti (2021). Guía para la elaboración de materiales educativos II. Piezas sonoras. Editorial: Secretaría de Extensión Social y Cultural. Universidad Nacional del Litoral. Link de descarga gratuita: https://hdl.handle.net/11185/5854

\section{Por Oscar Enrique Bosetti \\ Universidad de Buenos Aires. Universidad Nacional de Entre Ríos. Universidad Nacional de Quilmes, Argentina. oscarbosetti@hotmail.com (iD orcid.org/0000-0002-5593-6901}

Ambiente y extensión universitaria /

En un artículo provocativo, movilizador, Manuel Alonso ${ }^{1}$ plantea que resulta imposible imaginar una existencia sin sonido. Estemos donde estemos, sea el ámbito más privado como el más público, "cuando logremos liberarnos del predominio del mundo visual-analítico y lo reemplazamos por las intuiciones y la sensación, comenzamos a descubrir nuevamente la verdadera afinación del mundo y la exquisita armonía de todas sus voces". Así como primero fue el sonido y luego la palabra, resulta incuestionable que, desde el origen mismo del universo, existió el sonido.

En otro texto que marcó poderosamente las reflexiones inaugurales en torno al ecosistema radiofónico, el filósofo berlinés Rudolf Arnheim (1904-2007) fundó el concepto de radiofonicidad y lo definió "como un modelo para crear, según sus propias leyes, un mundo acústico de la realidad".

Esa materia prima comunicacional aún perdura y goza de buena salud. Mantiene su vigencia y no ha perdido su espesura en las diversas prácticas comunicativas existentes, incluso en estos tiempos de acechantes multiplataformas. Esta necesaria Guía para la elaboración de materiales educativos y comunicacionales recupera el lugar de las piezas sonoras y revaloriza su centralidad protagónica al momento de imaginar rumbos y acciones en las arenas de la extensión universitaria.

Durante mucho tiempo esa caracterización sirvió para abordar y orientar los estudios referidos a la comunicación radiofónica desde una impronta que el autor de Estética Radiofónica diseñó con rigor epistemológico, y desde su profunda comprensión del significado del arte, alcanzó una aguda conciencia de las ventajas y desventajas de los modos lingüísticos y no lingüísticos de la comunicación. Planteado de otro modo, desde esta perspectiva fundante, el relato radiofónico se integra con componentes verbales y no verbales. Es decir, con elementos lingüísticos o sonidos fonéticos organizados (las palabras articuladas), sonidos periódicamente organizados (los usos de la música), sonidos específicos del entorno de objetos y acontecimientos (los efectos sonoros), y tramos sin señal vibratoria, fragmentos temporales insonoros que resultan valorables en sí mismos como elementos activos de una secuencia temporal de carácter significativo (los silencios).

Ciertamente, ese uso inicial de la mirada arnheiniana se amplió y enriqueció en este clima epocal del siglo XXI donde las narrativas transmedias evanecieron los contornos de lo estric-

1) http://www.ccapitalia.net/reso/articulos/entorno_sonoro/entorno_sonoro.htm 
tamente sonoro y audiovisual para convivir en este actual territorio de hibridaciones y estimulantes propuestas que pusieron en cuestionamiento la noción del significante radio, tal como fue pergeñada hacia 1920, cuando ese grupo de pioneros del medio inició este recorrido de 101 años de obstinada vigencia.

Con este contorno de referencias e inocultables contraseñas se inscribe esta necesaria Guía para la Elaboración de Materiales Educativos y Comunicacionales, donde las piezas sonoras adquieren una centralidad protagónica al momento de imaginar rumbos y acciones en las arenas de la extensión universitaria, una de las columnas liminares que sostiene la razón de ser de las prácticas universitarias desde los postulados de la Reforma de 1918.

Aun en tiempos de predominio de las pregnantes, múltiples y ubicuas pantallas, desde su dimensión exclusivamente acústica, las piezas sonoras deben conformarse en un medio de carácter multisensorial. La estimulación que activa el sentido auditivo está en condiciones de facilitárselo mediante sus amplias facultades evocadoras y creadoras.

Por eso, esta Guía alienta un repertorio de producciones que reconocen la matriz de la sonoridad radiofónica y convoca a las nuevas arquitecturas de los géneros y formatos para generar contenidos socialmente significativos. Allí se alistan los podcasts y los audiolibros, los docudramas y los radiodramas, los informes y las entrevistas periodísticas, las cuñas institucionales y las que sostienen una campaña de bien público, entre otras posibles opciones orientadas a los fines tanto educativos como comunicacionales en general. 